I am trying to show is only that an obligation to prevent predation can be given a non-utilitarian foundation.

5. The Case for Animal Rights, p. 325 .

6. Morals, Reason, and Animals, p. 231.

7. Ibid., pp. 233-234.

8. Ibid., p. 234 .

9. Ibid., p. 235. Sapontzis is quoting from Aldo Leopold, $\underline{A}$ Sand County Almanac, pp. 224-225.

10. Morals, Reason, and Animals, p. 235.

11. Ibid., p. 265.

12. "Animal Liberation: A Triangular Affair." p. 311-336.

13. Ibid. p. 312

14. Ibid.. pp. 311 and 337.

15. Morals, Reason, and Animals, p. 268.

16. Ibid., p. 263.

17. Sapontzis makes similar remarks throughout pp. 262-267 of Morals, Reason, and Animals.

18. "Animal Liberation: A Triangular Affair," p. 333.

19. Ibid.

20. Morals, Reason, and Animals, pp. 264-265.

21. Ibid., p. 271

22. This phrase is Sapontzis'. See Morals, Reason. and Animals. p. 269.

\section{ENVIRONMENTAL ETHICS AND THE LOCUS OF VALUE}

\author{
S. F. Sapontzis \\ California State University, Hayward
}

In "Realism and Respect," Professor Baldner attempts to defend holistic environmental ethics against criticisms I made of it in my book, Morals, Reason, and Animals (Philadelphia: Temple University Press, 1987). While I very much appreciate the care Professor Baldner has given to accurately stating and thoughtfully critiquing my views, I do not find that critique compelling for the following reasons.

First, the fundamental, theoretical flaw in environmental ethics of the sort Baldner advocates is the belief that values can exist without reference to the capacities of sentient beings. The prevalence of this mistaken belief among environmental ethicists may be due to the use of "value" in phrases like "its value for evolution." In such phrases "value" refers to the role played by something in evolution. This role can be completely explicated in non-evaluative descriptions of how this thing interacted with other things to contribute to the course of evolution. That this can be done shows that the term is being used non-evaluatively in such phrases. Where evaluation enters here is in the presumption that the course or products of evolution are good, fulfilling a purpose, or otherwise worthy. That is a value something has not merely "for evolution" but for a sentient being contemplating evolution.

Baldner attempts to support his value theory by contending that "if the existence of the natural

\section{A Reply to Kent Baldner's "Realism and Respect"}

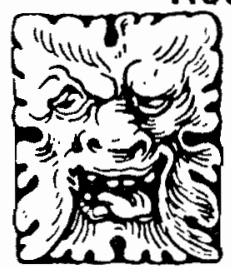


environment is not dependent upon us, neither is its value." However, this contention is false. Values are supervenient properties; it follows that things can exist without value and that the source of their existence can differ from the source of their value. Once again, Baldner's mistake here may be due to confusing playing a role with having value: he holds the natural environment to comprise a system; consequently, anything that comes to exist in that environment will be playing a role in a system. Once again, playing a role is not the same as having value; on a world where sentient life arises, which no sentient being visits, and which otherwise has no effect on sentient life, the wind may play a role in the geological evolution of the topography, but there is no value to it. There is merely the replacement of one configuration by another.

Second, Baldner sees focusing on sentience in value theory as unjustifiably holding that sentient beings are especially "important" by virtue of being "similar to human beings" (lingering anthropocentrism). This is doubly wrong. Sentient beings are not at the center of a consistent and adequate value theory because they are more important than nonsentient beings or environments; they are at the center because it is through their relations to sentient beings that things come to have value. Furthermore, there is nothing anthropocentric here; being sentient is not a relational property. Describing a being as sentient is no more comparing it to humans than is saying it has a mouth. A moral philosopher does not have to be misanthropic in order not to be anthropocentric.

Third, like other environmental ethicists, Baldner seems to envisage only two ways in which nature may be morally evaluated: either nature is merely a resource to be cut down, dug up, and otherwise transformed and consumed to fulfill human desires, or nature has overriding value of its own, is an end-in-itself which must be preserved as is. This is a false dilemma; we can recognize that the value of nature is not limited to being a resource for human consumption without regarding it as an end-in-itself. First, we can acknowledge that nature is of value for sentient but nonhuman beings. Second, we can recognize that many humans value nature remaining as it is; they value contemplating or communing with nature, not just consuming it. Finally, we can recognize that preserving natural systems is important for preserving our own existence; the uninhibited consumption of natural resources may leave us unable to sustain ourselves. Thus, one can share the environmentalists' love of nature and dismay at its continuing destruction at the hands of human profiteers and can develop moral philosophies which accommodate those feelings without having to regard the natural environment as an end-in-itself.

Finally, Baldner contends that is "arrogant" and "paternalistic" morally to condemn something as definitive of the natural order as predation. However, it is in the nature of morality to devise ideals of a better world and to work toward realizing them. This entails judging this world to be less than ideal and working to change it. One could restrict moral evaluations to the products of human activity, but that would be arbitrary: what makes suffering (prima facie) morally bad is not that it is the result of human activity but that it is suffering. Our commitment to making the world a morally better place impels us to make moral evaluations of the natural order. There need be nothing either arrogant or paternalistic in making and acting on such evaluations, provided we recognize the very limited nature of our understanding and our power to make improvements.

Of course, we could give up the moral enterprise altogether and maintain that whatever is is right. But even environmental ethicists seem unwilling to do this, since they are intent on condemning attitudes which have been definitive of Western culture and on substantially transforming that culture. Is this arrogant and paternalistic on their part?

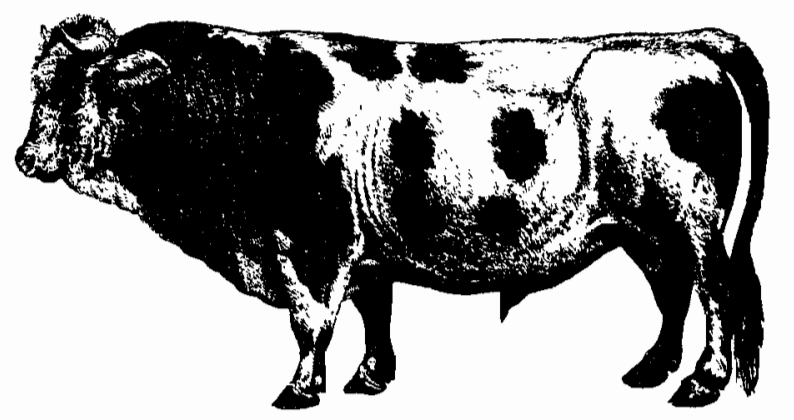

